\title{
The effects of varying the extent of the vagotomy on the myoelectrical and motor activity of the stomach ${ }^{1}$
}

\author{
C. J. STODDARD, W. E. WATERFALL, B. H. BROWN, AND H. L. DUTHIE \\ From the University Surgical Unit, Sheffield Royal Infirmary
}

SUMMARY The effects of varying the extent of vagotomy on the myoelectrical and motor activity of the stomach have been successfully studied in 21 patients undergoing either truncal, selective, or highly selective vagotomy for the treatment of chronic duodenal ulceration. The mean percentage time that regular antral myoelectrical activity was recorded preoperatively was $95.8 \% \pm 1.0$ and this was decreased following highly selective vagotomy $(74.0 \% \pm 6 \cdot 6)$, selective vagotomy $(37 \cdot 8 \% \pm$ $12 \cdot 4)$, and truncal vagotomy $(30.2 \% \pm 10.4)$. The mean amplitude of the pacesetter potential was less following truncal $(0.86 \mathrm{mV} \pm 0.05)$, selective $(1.32 \mathrm{mV} \pm 0.09)$, and highly selective vagotomy $(1.67 \pm 0.09)$ than in preoperative studies $(2.21 \mathrm{mV} \pm 0.12)$. Following truncal and selective vagotomies the triphasic waveform of the pacesetter potential changed to a sinusoidal shape. No significant change in the mean preoperative frequency of the myoelectrical activity $(3.03 \mathrm{cpm} \pm 0.08)$ occurred after vagotomy. Thus the changes in the electrical activity of the stomach are related to the extent of the vagal denervation. Intravenous administration of insulin did not alter these patterns except after highly selective vagotomy when the amplitude of the electrical waves, the incidence of action potentials, and percentage motor activity were increased.

It is now well established that there exists in the distal two-thirds of the stomach in man an omnipresent rhythm of electrical waves known as the pacesetter potential or slow wave activity which has a frequency of approximately 3 cycles per minute. The waveform has a characteristic morphology and has been previously described by Kwong, Brown, Whittaker, and Duthie (1970) and Couturier, Rozé, Paolaggi, and Debray (1972). An initial biphasic fast component lasting two to five seconds is followed by a slow component lasting longer than nine seconds, this division into two parts being especially clear in antral recordings. Motor activity when present is associated with the occurrence of spike activity or action potentials which are superimposed on the basic slow wave activity.

Previous reports have not had uniform findings of the effect of vagotomy on the gastric electrical activity either in man (Morton, 1954; McIntyre, Deitel, Baida, and Jalil, 1969; Kwong et al 1970) or in the canine stomach (Nelsen, Eigenbrodt, Keoshian, Bunker, and Johnson, 1967; Nagoaka, 1968; Kelly and Code, 1969). In this present series we have used

\footnotetext{
1 Based on a communication to the Surgical Research Society, January 1973.

Received for publication 31 May 1973.
}

mucosal electrodes in conscious subjects to study the changes which are present in the gastric myoelectrical and motor activity five days postoperatively in three groups of patients who have undergone different extents of abdominal vagal denervation.

\section{Methods}

A total of 31 patients, 26 males and five females, aged 25 to 61 years, were studied. All patients were undergoing surgical treatment for chronic duodenal ulceration and gave informed consent for the performance of these investigations. No patients who received emergency surgery were included in the series.

After an overnight fast a modified nasogastric tube was passed orally into the gastric antrum under radiographic control and attached to the gastric mucosa by suction. The nasogastric tube used was identical to that previously employed in this department (Kwong, Brown, Whittaker, Duthie, 1972). monopolar recordings of the gastric electrical activity being recorded from a stainless steel electrode situated $1 \mathrm{~cm}$ from the tip of the tube. Signals from the electrode were fed into an ac amplifier with a frequency response within \pm 657 
$3 \mathrm{~dB}$ from $0.016 \mathrm{~Hz}$ to $1.0 \mathrm{KHz}$ and displayed on a uv recorder at a sensitivity of $1 \mathrm{mV}$ per cm deflection. Synchronous outputs were transmitted to two filters with respective frequency response ranges of 2 to 6 and 9 to $14 \mathrm{cpm}( \pm 3 \mathrm{~dB}$ from 0.02 to 0.1 and 0.15 to $0.23 \mathrm{~Hz}$ ). The outputs of these filters were also recorded. As with previous recordings in this department gastric motility was measured by the open-tipped catheter technique using a strain gauge pressure transducer. Gastric secretion was continuously aspirated via an attached tube, the first opening of which was situated $6 \mathrm{~cm}$ proximal to the electrode.

The patients were placed in a semirecumbent position and following a lapse of $\mathbf{3 0}$ minutes, to allow the effects of intubation to pass, recordings were commenced. Nine patients underwent a 60minute preoperative recording without the injection of any pharmacological agent. Postoperative testing was attempted on the fifth postoperative day in $\mathbf{3 1}$ patients, from whom acceptable results were obtained in 21 cases. In the other 10 patients, eight were unable to tolerate the tube for a sufficient period to obtain clear records, one had a positive insulin test, and the last had a recording made from the duodenum. In all of the remaining 21 patients a 60-minute recording was made and this was followed in 14 patients by an iv injection of soluble insulin 0.2 iu per $\mathrm{kg}$ body weight and a further two hours recording in 12 patients and one hour recording in two others. All 21 patients had a negative gastric secretory response to the insulin either at this test or at a separate gastric secretory study. The number of patients in each of the three groups is shown in table I.

\begin{tabular}{lcc}
\hline Vagotomy & Total No. & No. Given Insulin \\
\hline Truncal & 9 & 6 \\
Selective & 6 & 4 \\
Highly selective & 6 & 4 \\
Totals & 21 & 14 \\
\hline
\end{tabular}

Table I Number of patients in each group

\section{Results}

\section{RESTING STUDIES}

\section{Electrical activity}

In the nine patients tested preoperatively the pacesetter potential had a normal triphasic waveform which was present for greater than $90 \%$ (mean $95.8 \% \pm 1.04$ ) of the recording period (fig 1). The frequency range of this electrical activity was $2 \cdot 8$ to 3.3 cycles per minute (mean $3.03 \pm 0.08 \mathrm{cpm}$ ) but in no patient did it vary by more than $5 \% \pm$ during the test. Action potentials accompanied 11 to $33 \%$ of the basic electrical waves (mean 19.4 \pm ) and were usually superimposed on the slow component of the pacesetter potential. They were always accompanied by pressure waves, the commencement of the upstroke of a pressure wave coinciding with each action potential. The amplitude of the pacesetter potential showed some slight variation in each patient with a mean of $2 \cdot 21 \mathrm{mV} \pm 0 \cdot 12$. When action potentials occurred the amplitude of the pacesetter potential increased, sometimes up to two and a half times the mean value of those waves without associated spike activity. Although only nine patients were tested preoperatively all recordings of the myoelectrical activity were virtually identical with previous

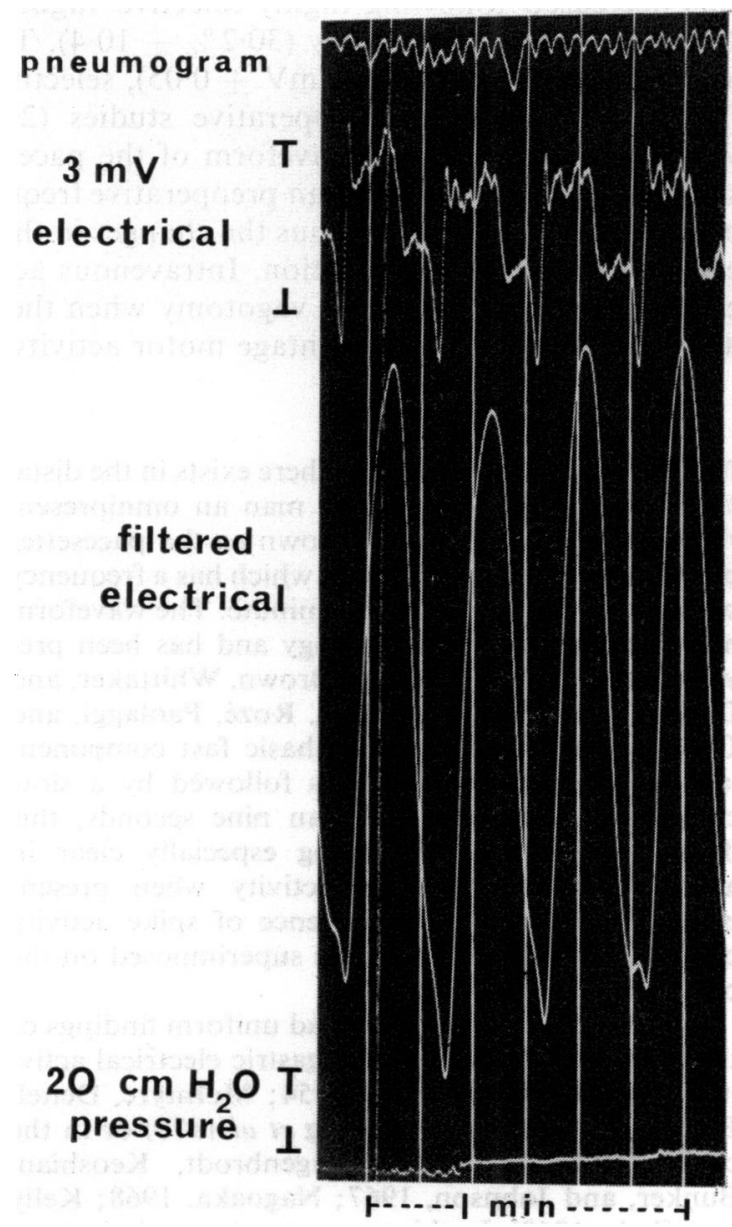

Fig 1 Preoperative recording of electrical activity from the gastric antrum showing the normal triphasic pacesetter potential with a frequency of 3.09 cycles per minute. No action potentials or motor waves are present. 
measurements made in this department and the comparisons may therefore be considered valid for the whole group. In a series of 10 patients reported by Duthie, Kwong, Brown, and Whittaker (1971) regular antral electrical activity was present for almost the entire duration of each recording with a mean frequency of $3.12 \pm 0.05 \mathrm{cpm}$ and amplitude of $2 \cdot 27 \pm 0.30 \mathrm{mV}$.

\section{Motor activity}

Motor waves were recorded in all patients. The percentage motor activity ranged from 6 to $17 \%$ (mean $9.9 \%$ ), the pressure waves usually occurring in bursts of one to two minutes' duration when they accompanied each cycle of the pacesetter potential. The apparent discrepancy between the percentage of the pacesetter potential showing action potentials and the percentage time that motor waves were present is due to the fact that the pacesetter potential is of about 20 seconds' duration and the motor waves last only 10 seconds.
FOLLOWING VAGOTOMY

\section{Electrical activity}

Following all types of vagotomy there was no significant change in the frequency of the pacesetter potential. The mean frequency in all three groups was marginally greater than in the preoperative recordings but in none of the groups was this greater than the range of frequency variation which can usually be expected (table II).

\begin{tabular}{lll}
\hline & Vagotomy & Mean Frequency (cpm) \\
\hline Preoperative & & $3.03 \pm 0.08$ \\
Postoperative & HSV & $3.18 \pm 0.07$ \\
& SV & $3.08 \pm 0.12$ \\
& TV & $3.09 \pm 0.06$ \\
\hline
\end{tabular}

Table II Mean frequency of the pacesetter potential in each group of patients studied preoperatively and following truncal (TV), selective (SV), and highly selective (HSV) vagotomy.

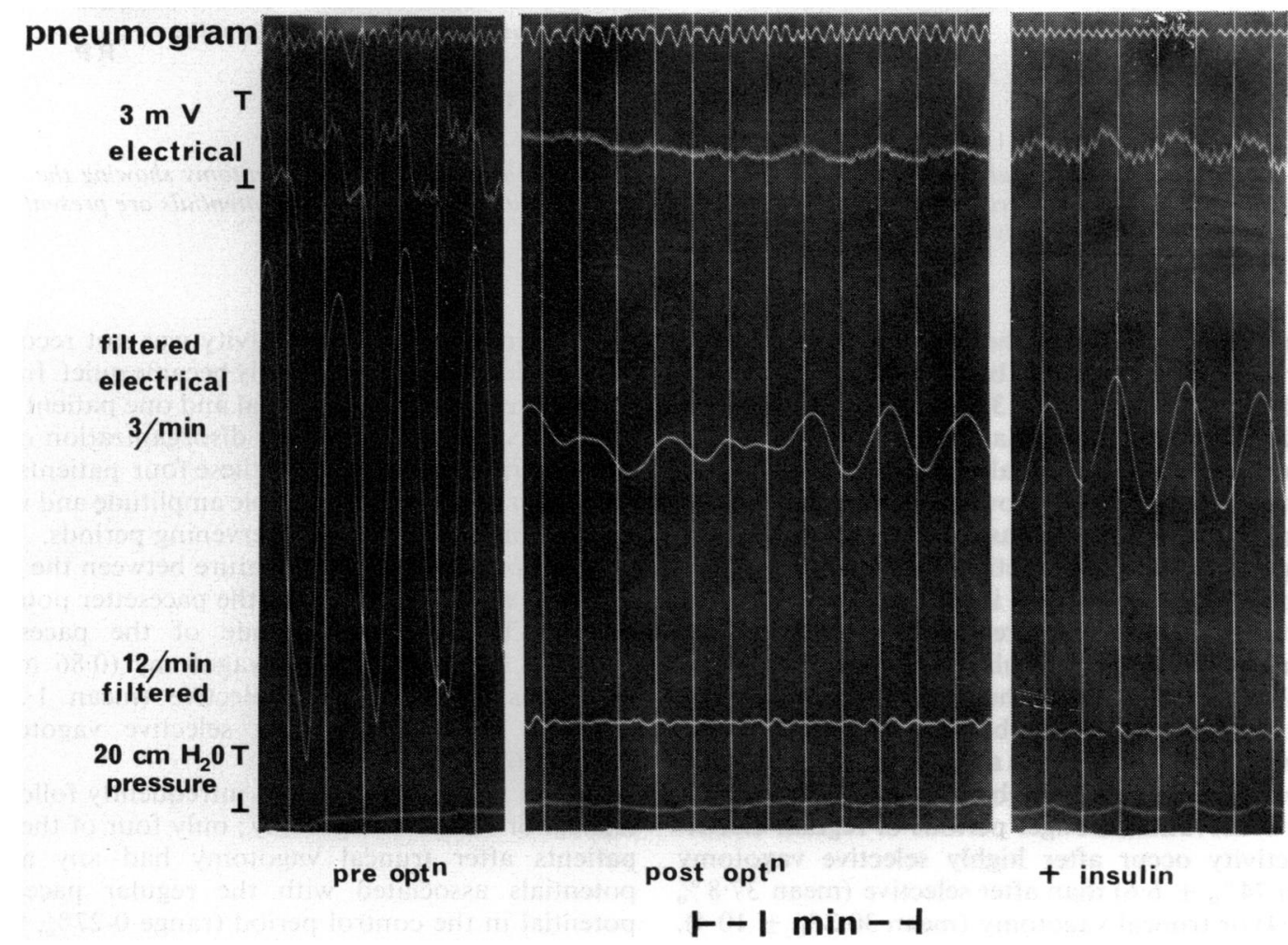

Fig 2 Recordings of electrical activity from the gastric antrum before and after truncal vagotomy. Postoperatively the pacesetter potential has a reduced amplitude, a sinusoidal wave-shape, and is not present for the whole recording. 

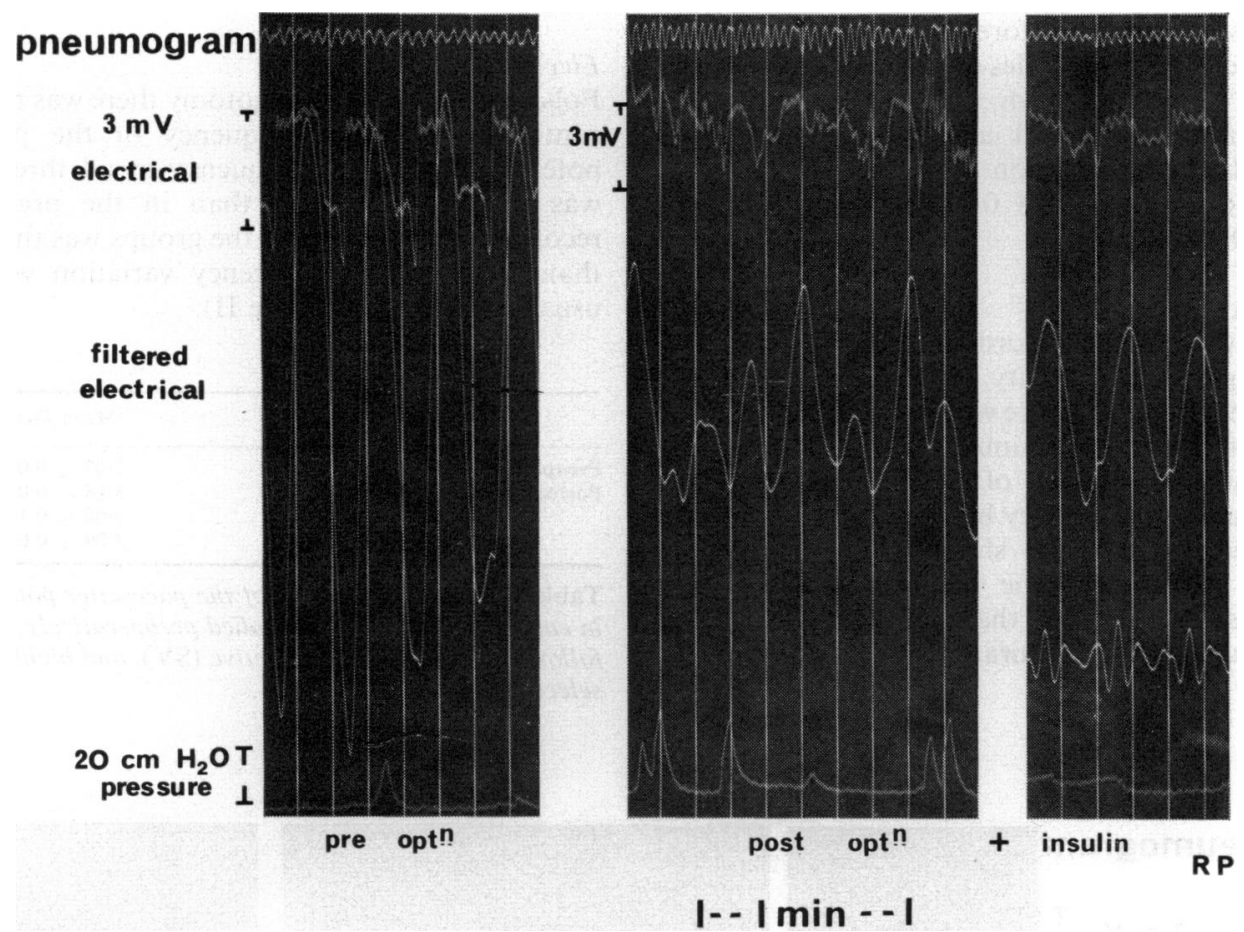

Fig 3 Recordings of electrical activity from the gastric antrum before and after selective vagotomy showing the sinusoidal wave shape and decreased amplitude of the pacesetter potential. Numerous action potentials are present and are associated with motor activity.

There was a change in the waveform of the pacesetter potential following both truncal (fig 2) and selective vagotomies (fig 3 ). In both groups the normal triphasic wave-shape seen preoperatively was replaced by a sinusoidal wave. Following highly selective vagotomies, however, the pacesetter potential retained its triphasic configuration (fig 4).

Regular myoelectrical activity was not present for the entire recording period in any patients following vagotomy. Although there was a scatter in the percentage time that regular pacesetter potentials could be seen in both the selective and truncal vagotomy groups it can be seen from fig 5 that following operation there is a trend for the occurrence of myoelectrical activity to be related to the degree of vagal denervation. Longer periods of regular electrical activity occur after highly selective vagotomy (mean $74 \% \pm 6.6$ ) than after selective (mean $37.8 \%$ $\pm 12 \cdot 4$ ) or truncal vagotomy (mean $30 \cdot 2 \% \pm 10 \cdot 4$ ). Regular myoelectrical activity is thus present for a smaller percentage of the time when vagal denervation of the stomach has been most extensive. During the time in which regular activity was not recognizable the electrical record usually became quiet. In only three patients following truncal and one patient after selective vagotomies did any disorganization of the myoelectrical activity occur; these four patients had pacesetter potentials of variable amplitude and waveshape morphology in the intervening periods.

The most distinguishing feature between the three groups was the amplitude of the pacesetter potential (fig 6). The mean amplitude of the pacesetter potential following truncal vagotomy $(0.86 \mathrm{mV} \pm$ 0.05 ) was less than after selective (mean 1.32 \pm 0.09 ) or than after highly selective vagotomies (mean 1.67 \pm 0.09 ).

Action potentials occurred infrequently following truncal or selective vagotomy; only four of the nine patients after truncal vagotomy had any action potentials associated with the regular pacesetter potential in the control period (range $0-27 \%$, mean $5.1 \%$ ) and following selective vagotomy spike activity was seen in only one patient for $5 \%$ of the recording. Following highly selective vagotomy action poten- 
tials occurred more frequently in all patients (mean $12 \cdot 4 \% \pm 6 \cdot 1)$.

Thus following the three types of vagotomy we have found that there is no significant change in the frequency of the pacesetter potential but that its wave shape is altered following truncal and selective vagotomies and the occurrence of action potentials is decreased. The most constant changes are a decrease in the percentage time that regular myoelectrical activity is present and a decrease in the amplitude of the pacesetter potential, both of which are related to the degree of vagal denervation (fig 7).

\section{Motor activity}

Fewer motor waves occurred in the antrum after all three types of vagotomy (fig 8). Only three patients after truncal vagotomy exhibited any motor activity during the control period, this occurring for a mean time of $2 \cdot 3 \% \pm 1 \cdot 5$. Following selective vagotomy motor waves were present for $4.8 \% \pm 1.3$ of the recording time. One patient in the latter group had motor activity for $29 \%$ of the time but this was unassociated with any spike activity and was considered to be an artefact. Following highly selective vagotomy motor waves were present in five patients for a mean percentage time of $8 \cdot 4 \% \pm 3 \cdot 3$, which is

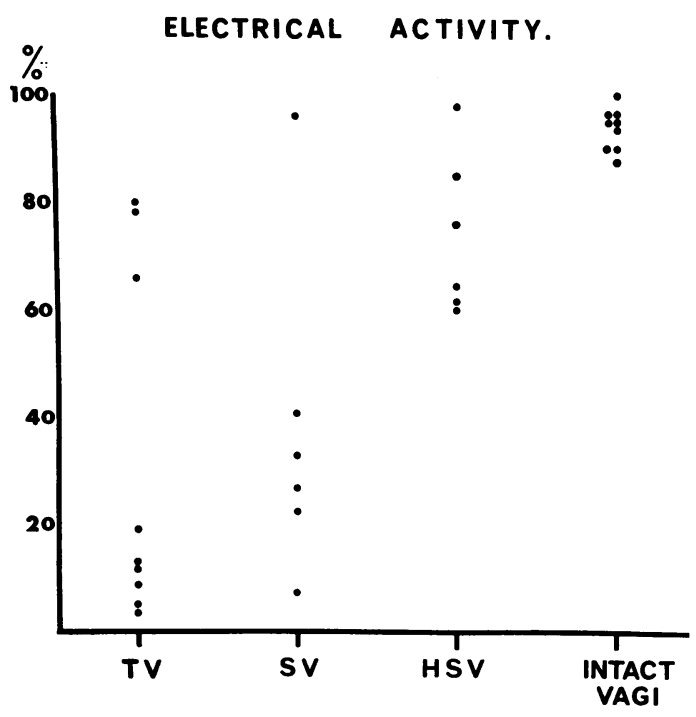

Fig 5 The percentage time during which regular myoelectrical activity was present during the 60-minute control period in preoperative patients with intact vagi and following three types of vagotomy (TV, truncal vagotomy, SV, selective vagotomy, and $\mathrm{HSV}$, highly selective vagotomy).

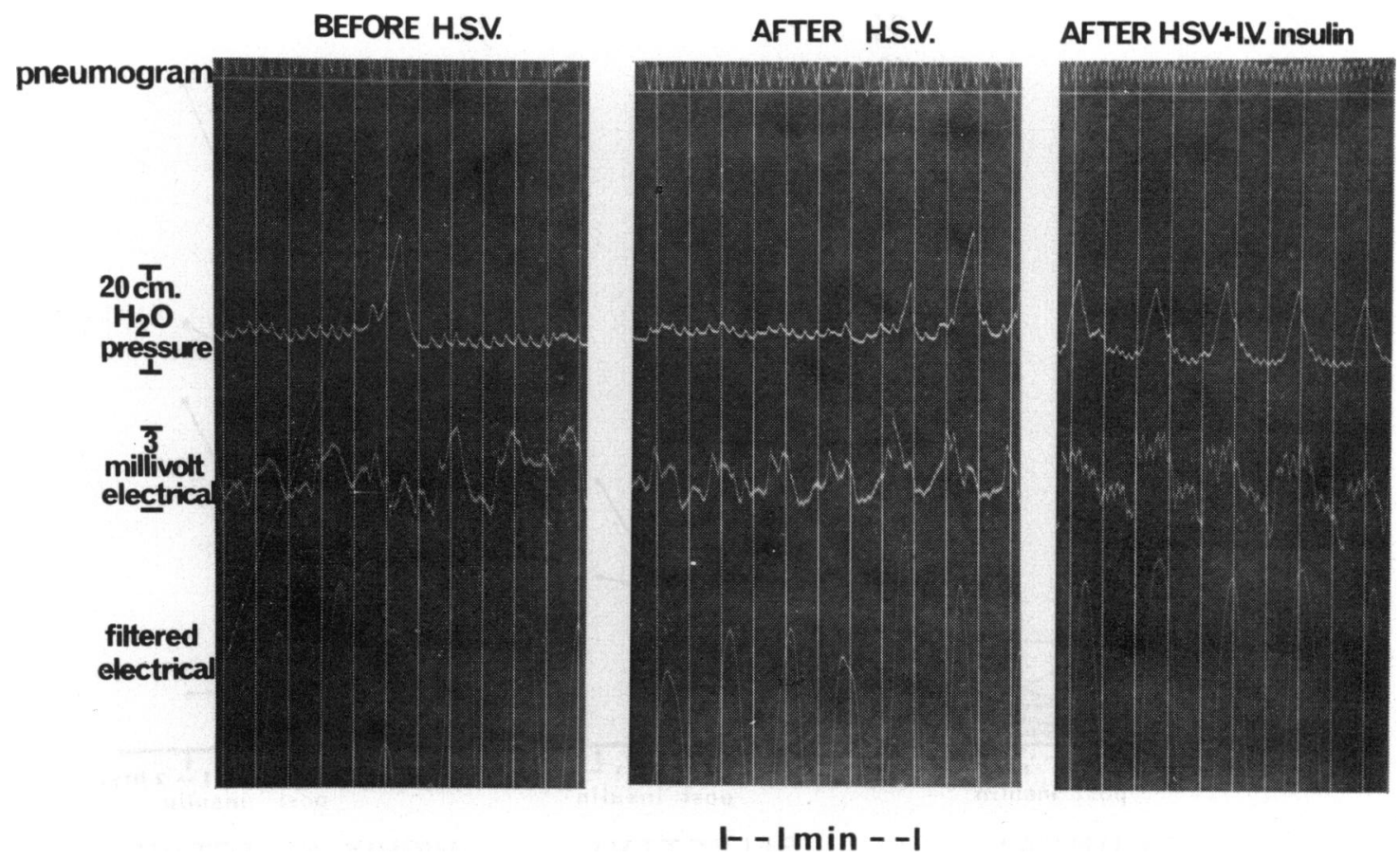

Fig 4 Recording of electrical activity from the gastric antrum after highly selective vagotomy showing regular pacesetter potentials throughout the record with a normal triphasic wave shape and only a slight decrease in amplitude. Action potentials and motor activity are increased after intravenous insulin. 


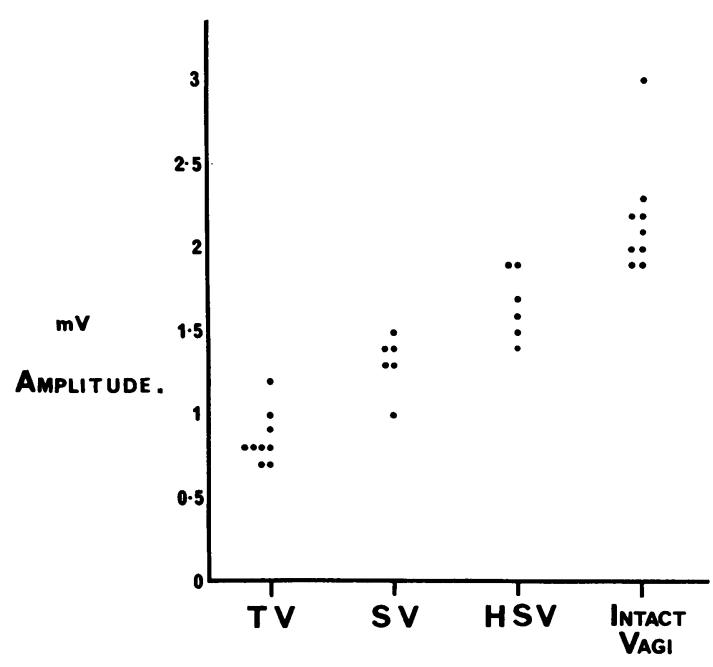

Fig 6 Mean amplitude of the pacesetter potential in millivolts $(\mathrm{mV})$ in preoperative patients with intact vagi and after truncal, selective, and highly selective vagotomies. The amplitude of the pacesetter potential is smaller when the vagal denervation is the most extensive.

\section{MOTOR}

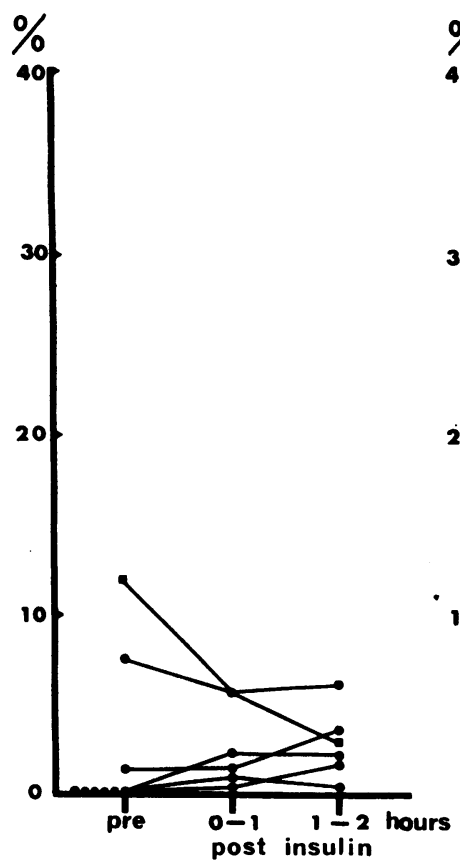

TRUNCAL.

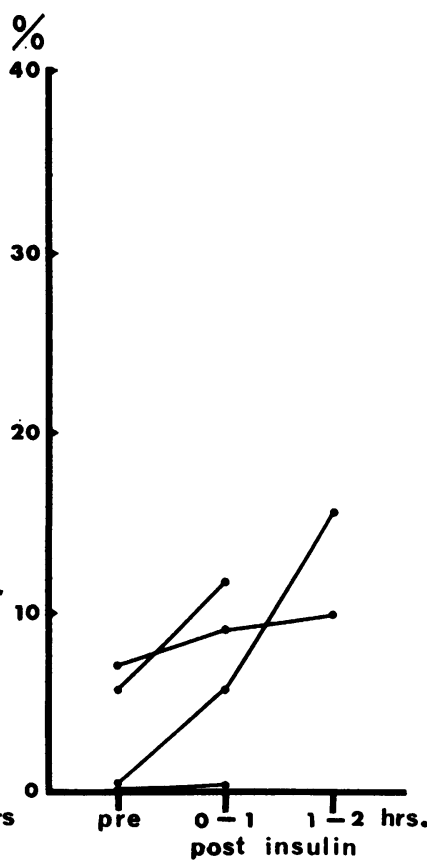

SELECTI VE.

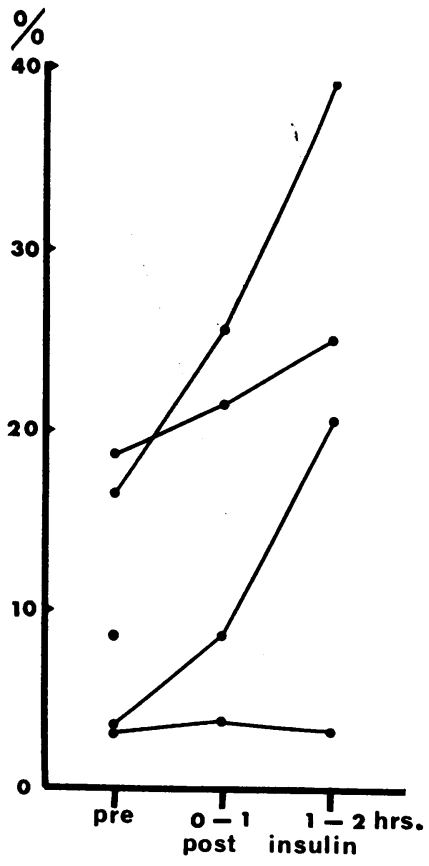

HIGHLY SELECTIVE.

Fig 8 The percentage motility for each patient during the control period and for two hours following intravenous insulin after the three types of operation. Insulin produced no significant change in the motor activity after truncal vagotomy but after highly selective vagotomy the motor activity increased in three patients.

Fig 7 Mean amplitude of the pacesetter potential in millivolts $(\mathrm{mV}$ ) plotted against the mean percentage occurrence of regular gastric electrical activity for each of patients studied in the preoperative stage and following truncal, selective, and highly selective vagotomies. 
only slightly less than the mean preoperative motor activity (mean $9.9 \%$ ). No motor activity was recorded in the other patient following highly selective vagotomy but this was later found to be due to a fault with the constant infusion pump.

\section{FOLLOWING INSULIN INJECTION}

There was no change in the myoelectrical or motor activity of those patients who had undergone truncal vagotomy. In the small number of patients who received insulin following selective and highly selective vagotomies there was a tendency for the mean amplitude of the pacesetter potential, number of action potentials, and motor activity to increase. The changes were more conclusive following highly selective vagotomy.

\section{Discussion}

In this report we have compared the effects of three different extents of gastric vagotomy on the myoelectrical activity of the stomach. In two groups, namely, after truncal vagotomy and after selective vagotomy, a pyloroplasty was also performed. It is generally agreed the pyloroplasty itself has no effect on the electrical activity in the gastric antrum in animals (Shiratori, Sugawara, and Kuroda, 1965; Khan and Bedi, 1972) and we have previously confirmed this in one patient who is not included in this series. Thus it is permissible to compare the three types of vagotomy.

No clear pattern of changes in electrical activity of the stomach after vagotomy has emerged from previous animal studies. The reports range from no change in acute experiments (Nagoaka, 1968) to a temporary disorganization for a few days (Kelly and Code, 1969) or a more persistent disorganization lasting up to nine weeks in chronic preparations (Nelsen et al, 1967). Similarly, in man, Morton (1954) found a silent recording after vagotomy whereas McIntyre et al (1969) observed no change after vagotomy in intraoperative studies. We have noted two main alterations in the gastric electrical activity depending on the extent of the vagal denervation: first, a disturbance of the pacesetter potential so that it is present for part of the recording time ranging from $30 \%$ after truncal vagotomy to $75 \%$ after highly selective vagotomy, and secondly, a change in the pacesetter potential wave shape and reduction in its ampitude. The wave became more sinusoidal instead of the triphasic form found in the intact stomach. The antral records we have obtained after vagotomy resembled those reported as occurring in the more proximal stomach in normal subjects (Couturier et al 1972). Our patients were studied at five days after operation and preliminary longer-term results indicate that some of the changes persist for several months.

Although most patients had a disturbance of the pacesetter potential following vagotomy three patients after truncal and one patient after selective vagotomies had long periods of regular electrical activity for which three theoretical explanations are possible. There may have been no disturbance of the myoelectrical activity, or secondly, the disturbance had been only temporary and by the fifth postoperative day was reverting back to normal, as suggested by Kelly and Code (1969). Finally, the negative gastric secretory responses in these patients may in fact be a false negative result and intact gastric vagal innervation persists. We consider the last suggestion unlikely as one patient with a positive secretory response whom we studied after a probable incomplete truncal vagotomy had, in contrast to those patients with a negative response, a marked increase in motor activity after intravenous insulin. Further studies at earlier and later postoperative stages will probably eventually help to elucidate the true explanation.

We have no direct evidence on the possible mechanism of the changes following vagotomy but it is suggested that they result from an alteration in the balance between the vagal and sympathetic nervous supply to the stomach. Changes in the amplitude of gastric electrical activity similar to our findings has been described after administration of atropine or adrenaline in dogs (Daniel, Wachter, Honour, and Bogoch, 1960). With regard to the disturbance of the pacesetter potential, this can be explained on the hypothesis that the electrical activity of the smooth muscle of the stomach can be compared to a matrix of coupled relaxation oscillators (Sarna, Daniel, and Kingma, 1972). The vagotomy may alter the degree of coupling between oscillators so that they do not act continually in concert and so the regular pacesetter potential rhythm of $3 / \mathrm{min}$ is seen only intermittently.

From a clinical standpoint, the fact that highly selective vagotomy is followed by the least disruption of the electrical activity of the gastric antrum would add support to the basic concept of the operation that preservation of the vagal nerves to the antrum will ensure its normal motor function.

We acknowledge the support of the Medical Research Council for technical assistance.

\footnotetext{
References

Couturier, D., Rozé, C., Paolaggi, J., and Debray, C. (1972). Electrical activity of the normal human stomach: a comparative study of the recordings obtained from the serosal and mucosal sides. Amer. J. dig. Dis., 17, 969-976.

Daniel, E. E., Wachter, B. T., Honour, A. J., and Bogoch, A. (1960).
} 
The relationship between electrical and mechanical activity of the small intestine of dog and man. Canad. J. Biochem., 38, 777-802.

Duthie, H. L., Kwong, N. K., Brown, B. H., and Whittaker, G. E. (1971). Pacesetter potential of the human gastroduodenal junction. Gut, 12, 250-256.

Kelly, K. A., and Code, C. F. (1969). Effect of transthoracic vagotomy on canine gastric electrical activity. Gastroenterology, 57, $51-58$.

Khan, I. H., and Bedi, B. S. (1972). Effect of vagotomy and pyloroplasty on the interdigestive myoelectrical complex of the stomach. Gut, 13, 841-842.

Kwong, N. K., Brown, B. H., Whittaker, G. E., and Duthie, H. L. (1970). Electrical activity of the gastric antrum in man. Brit. J. Surg., 57, 913-916.

Kwong, N. K., Brown, B. H., Whittaker, G. E., and Duthie, H. L. (1972). Effects of gastrin I, secretin and cholecystokininpancreozymin on the electrical activity, motor activity and acid output of the stomach in man. Scand. J. Gastroent., 7, 161-170.
McIntyre, J. A., Deitel, M., Baida, M., and Jalil, S. (1969). The human electrogastrogram at operation: a preliminary report. Canad. J. Surg., 12, 275-284.

Morton, H. S. (1954). The potentialities of the electrogastrograph. Ann. roy. Coll. Surg., 15, 351-373.

Nagoaka, K. (1968). Electromyographic study of the mechanism of delayed gastric emptying after vagotomy in dogs. Tohoku J. exp. Med., 95, 1-13.

Nelsen, T. S., Eigenbrodt, E. H., Keoshian, L. A., Bunker, C. and Johnson, L. (1967). Alterations in muscular and electrical activity of the stomach following vagotomy. Arch. Surg., 94, 821-835.

Sarna, S. K., Daniel, E. E., and Kingma, Y. J. (1972). Simulation of the electric-control activity of the stomach by an array of relaxation oscillators. Amer. J. dig. Dis., 17, 299-310.

Shiratori, T., Sugawara, K, and Kuroda, S. (1965). Surgical significance of pyloroplasty with special reference to electromyographic findings. Tohoku J. exp. Med., 85, 192-200. 